\title{
IDENTIFICAÇÃO DOS GAPS DE UMA UNIDADE DE MANUFATURA UTILIZANDO O VSM PARA ATENDER UMA NOVA ESTRATÉGIA DE NEGÓCIO: UM ESTUDO DE CASO EM UMA EMPRESA DE REVESTIMENTO TÊXTIL
}

\section{IDENTIFICATION OF GAPS OF A MANUFACTURING UNIT USING VSM TO MEET A NEW BUSINESS STRATEGY: A CASE STUDY IN A COMPANY OF TEXTILE COATING}

\author{
Gisleine Schorn ${ }^{1}$; André Seidel ${ }^{2}$ \\ ${ }^{1}$ Universidade do Vale do Rio dos Sinos - UNISINOS - São Leopoldo/RS - Brasil \\ gisleine.schorn@gmail.com \\ ${ }^{2}$ Centro Universitário La Salle - UNILASALLE - Canoas/RS - Brasil \\ aseidel@unilasalle.edu.br
}

\begin{abstract}
Resumo
Atualmente o diferencial competitivo é definido a partir da decisão do que fazer melhor e diferente dos outros e isso implica, necessariamente, escolher, dentre um conjunto de atividades, as que têm maior potencial para agregar valor para a empresa (PAIVA, CARVALHO E FENSTERSEIFER, 2004). Dado este contexto, temos a unidade de manufatura da Empresa Alfa - uma empresa de revestimento têxtil, que está mudando sua estratégia de negócio para atender a mudança na forma de competir da organização. Frente a esse fato, o objetivo principal deste artigo é apresentar os gaps do processo de manufatura atual, através do uso do Value Stream Mapping - VSM, para atender a mudança na sua estratégia de negócio. Além disso, o artigo apresenta a trajetória da empresa e a nova estratégia de negócio da unidade de manufatura, detalhando o mapa do fluxo de valor atual e identificando os pontos de melhoria necessários para que a mesma seja bem sucedida. Dessa forma, este estudo caracteriza-se como uma pesquisa aplicada descritiva, onde o método de pesquisa utilizado foi o estudo de caso, com enfoque qualitativo, através da utilização dos sistemas de informações da organização, entrevistas e levantamento de informações in loco. Como resultado da pesquisa é apresentado o mapa do estado futuro desejado, detalhando um conjunto de ações para adequar a unidade de manufatura, tornando-a competitiva, para alavancar o resultado da empresa.
\end{abstract}

Palavras-chave: estratégia; estratégia de negócio; estratégia de operações; mapeamento do fluxo de valor; VSM.

\section{Introdução}


As organizações são levadas a constantes esforços de mudança pela busca incansável de adaptação ao meio competitivo, visando sua sustentabilidade. Quer sejam, movidas pelo simples instinto de sobrevivência, pela necessidade de tornarem-se competitivas, ou pelo desejo de manterem-se em posição de liderança, geralmente, os esforços de mudança têm sido na direção da identificação de uma configuração organizacional ajustada ao meio ou um modelo adaptado para os novos tempos de concorrência acirrada em mercados globalizados (DRUCKER, 1981).

Considerando este contexto, encontramos a unidade de manufatura da Empresa Alfa que vive um momento de adequação da sua estratégia de negócio para atender a mudança de posicionamento da corporação frente ao mercado. Hoje a empresa, que conta com uma unidade de manufatura que fabrica revestimento têxtil, mais especificadamente laminado sintético de poliuretano, e com uma distribuidora desse mesmo tipo de produto, sob a mesma identidade, é reconhecida como lançadora de moda para a indústria de calçados e acessórios, tendo como proposta de valor possuir todos os materiais lançados em suas coleções à pronta entrega. A fábrica, que para atender esse modelo, destina $80 \%$ de sua capacidade para a produção dos materiais necessários à manutenção do estoque da distribuidora, trabalhando apenas $20 \%$ para pedidos sob encomenda, não consegue mais os resultados esperados.

Assim, o objetivo central deste artigo é apresentar os gaps do processo de manufatura atual para atender a mudança planejada na sua estratégia de negócios, dando ênfase à forma como essa unidade, pode vir a tornar-se competitiva e passar a atender as necessidades organizacionais. Para conseguir chegar ao resultado esperado fez-se uso do VSM - Value Stream Mapping, ou seja, Mapeamento do Fluxo de Valor, que é uma é uma ferramenta que permite às empresas enxergar os seus desperdícios, servindo para direcionar as melhorias no fluxo que efetivamente contribuem para um salto no seu desempenho (FERRO apud ROTHER e SHOOK, 2003).

Como objetivos secundários foram definidos: (i) entender e contextualizar a nova estratégia de negócios da unidade de manufatura da Empresa Alfa; (ii) descrever a forma de atuação atual dessa unidade, apresentando seu desempenho, através da apresentação do mapa do fluxo de valor atual (VSM atual); e (iii) propor pontos de melhoria na manufatura para atender a nova estratégia a partir do desenho do mapa do fluxo de valor futuro (VSM futuro).

Para fundamentar o estudo, foram abordados os elementos fundamentais da estratégia de negócios, da estratégia de operações e a ferramenta do VSM - Value Stream Mapping, propriamente dita. O restante do artigo está organizado em: metodologia, resultados e conclusões do estudo.

\section{Estratégia de Negócios}


Segundo Porter (1991), a essência da formulação de uma estratégia competitiva é relacionar uma companhia ao seu meio ambiente. No entanto, segundo sua abordagem, embora o meio ambiente relevante seja muito amplo, abrangendo tanto forças sociais como econômicas, o aspecto principal é a indústria ou as indústrias em que ela compete. Para ele, o grau de concorrência em uma indústria depende de cinco forças competitivas básicas: entrada, ameaça de substituição, poder de negociação dos compradores, poder de negociação dos fornecedores e rivalidade entre os atuais concorrentes. Elas refletem o fato de que a concorrência não está limitada aos participantes estabelecidos - cliente, fornecedores, substitutos e os entrantes potenciais são todos "concorrentes" para as empresas, podendo ter maior ou menor importância dependendo das circunstâncias particulares.

Os fatores ambientais da empresa, interagindo com a unidade de negócios, continuamente criam o "caráter" da unidade, que são os compromissos internos criados como resposta às pressões. Avaliando seus pontos fortes e fracos se define a sua competência distintiva, ou seja, o que a distingue das demais e que pode ser decisivo para sua competitividade. Essa competência da organização é o que a ela pode particularmente fazer bem e a reconhecendo tem-se os elementos necessários para elaborar a estratégia de negócios. A estratégia de negócios refere-se a políticas, planos e objetivos de um negócio para se manter dentro de um ambiente complexo e competitivo. O sucesso da estratégia, segundo Rumelt et al. apud Paiva, Carvalho e Fensterseifer (2004) pode ser avaliado considerando:

- Consistência: a estratégia deve representar metas e políticas consistentes entre si;

- Consonância: a estratégia deve representar uma resposta adaptativa ao ambiente externo e às mudanças críticas ocorridas nele;

- Vantagem: a estratégia deve permitir a criação e a manutenção de uma vantagem competitiva no setor em que a organização atua;

- Viabilidade: a estratégia deve ser factível dentro dos recursos existentes e não deve criar problemas insolúveis.

\section{Estratégia de Operações}

Existem diversas definições para estratégia de operações, mas há certa concordância de que essa definição deve coincidir com os objetivos da unidade de negócios, alcançar os objetivos da área de operações, buscar uma vantagem competitiva e focalizar um padrão de decisões consistente no que se refere a operações. Para identificar estratégias genéricas de operações é preciso reconhecer as mudanças tecnológicas na área de operações e facilitar a ligação entre o tipo de sistema de operações e a orientação estratégica da unidade de negócio. Dessa forma, considerando o 
modelo de Porter (1986), é possível definir três estratégias genéricas de operações conforme apresentado na Figura 1: estratégia de liderança em custo pura, estratégia de diferenciação pura e estratégia de custo e diferenciação (PAIVA; CARVALHO e FENSTERSEIFER, 2004).

No caso de liderança em custo, pressupõe-se a necessidade de ganhos em escala desde a compra da matéria-prima e a produção até a negociação com os clientes. Ela é uma estratégia que exige instalações com escala eficiente, reduções de custo pela experiência e um rígido controle sobre custos e despesas gerais. Baixo custo em relação aos demais se torna o foco estratégico, embora não se ignorando qualidade e assistência.

Já a estratégia de diferenciação considera que o aspecto a ser buscado são características únicas e exclusivas do produto ou serviço oferecido pela empresa, criando algo que seja diferencial o âmbito competitivo no qual a empresa está inserida. A diferenciação, segundo Porter (1991), pode assumir diversas formas, tais como projeto ou imagem da marca, tecnologia, encomenda de serviços, fornecedores em rede ou outras dimensões.

Anteriormente considerava-se impossível uma empresa adotar estratégia de custo e diferenciação ao mesmo tempo, mas com os avanços tecnológicos isso já é possível. Quando os mesmos equipamentos podem produzir vários produtos, existe potencial de obtenção de economia de escopo. A tecnologia também viabiliza maior flexibilidade em projetos e mix de produtos, rápidas mudanças de mercado, maiores informações e mais rápida programação da produção. Essas competências permitem maior eficiência relacionada com maior variedade e não com maiores volumes.

Figura 1 - As três estratégias genéricas de operações

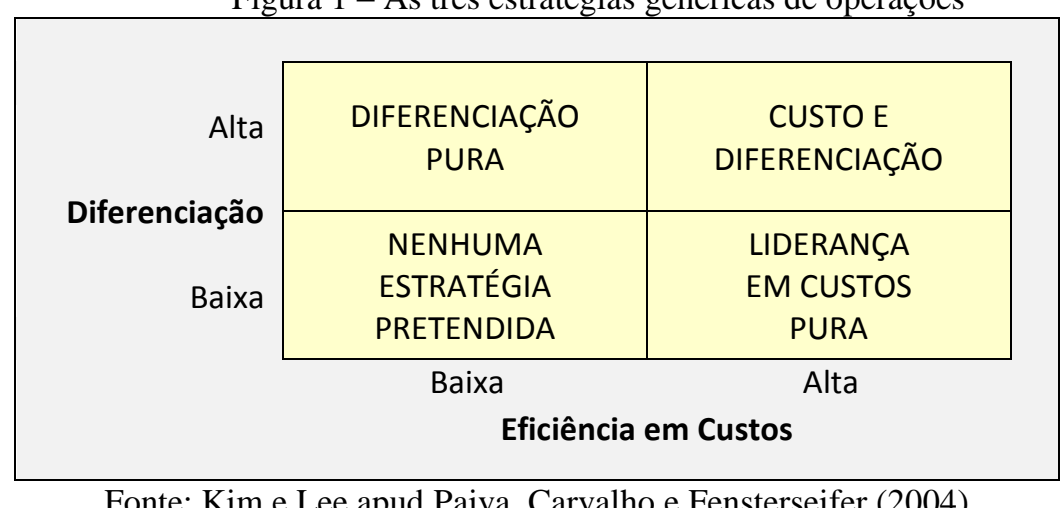

Fonte: Kim e Lee apud Paiva, Carvalho e Fensterseifer (2004)

Entendido isso, é preciso destacar que, em função dos elementos que compõem o sistema produtivo serem concebidos para atingir determinados fins e realizar determinadas tarefas, estratégias competitivas diferentes poderão exigir configurações distintas do sistema de produção. Neste sentido, cada tipo de estratégia demanda certas tarefas da produção e especifica determinados objetivos, os quais são conhecidos por "prioridades competitivas" e foram inicialmente 
identificados por Skinner (1969) como sendo produtividade, serviço, qualidade e retorno sobre investimento (MAIA, CERRA e ALVES FILHO, 2005).

Paiva, Carvalho e Fensterseifer (2004) tratam as prioridades competitivas como critérios competitivos e defendem que existem cinco critérios competitivos na área de operações que se relacionam à estratégia de negócio:

- Custo: capacidade de produzir com custos operacionais baixos;

- Qualidade: capacidade de entregar produtos / serviços de acordo com as especificações dos clientes;

- Flexibilidade: capacidade de adaptar o sistema de produção de acordo com as necessidades existentes;

- Entrega: capacidade de cumprir prazos prometidos;

- Inovação: capacidade de inovar em produtos e serviços oferecidos.

As empresas deveriam enfatizar a combinação de alguns desses critérios prioritariamente, pois a tentativa de atender simultaneamente a todas as dimensões pode ser perigosa, já que a definição dos critérios prioritários orientará a função de produção na definição do seu papel na estratégia competitiva da empresa.

Com base nesse fato, os critérios competitivos podem ser classificados em dois tipos: os critérios qualificadores, aqueles que devem estar num patamar mínimo exigido pelo mercado; e os critérios ganhadores de pedido, aqueles que devem oferecer desempenho melhor do que o da concorrência para que aumentem a competitividade da empresa e ganhem mercado da concorrência (HILL apud BARROS NETO, FENSTERSEIFER e FORMOSO, 2003). Vale enfatizar que a seleção entre critérios qualificadores e ganhadores de pedido dependerá das circunstâncias de cada mercado no qual a empresa atua.

Essas situações de decisão, em que escolhas por uma ou por algumas prioridades são inevitáveis, caracterizam a realização de trade-offs, que está associada às áreas de decisão estrutural e de infraestrutura, pois na tomada de decisão é preciso garantir que a alternativa selecionada seja apropriada às tarefas da manufatura. Por isso, para Paiva, Carvalho e Fensterseifer (2004), se uma empresa industrial deve escolher em quais dimensões competir, ela deve, por outro lado, orientar suas decisões e ações internas de forma coerente, para que, ao longo do tempo, essas ações e decisões em conjunto transformem-se em uma fonte de vantagem competitiva nas dimensões que a empresa optou em competir. Para facilitar o entendimento, segundo Wheelright (1984) apud Paiva, Carvalho e Fensterseifer (2004), essas decisões foram divididas em nove categorias:

- Capacidade: está relacionada às decisões a respeito da capacidade das instalações, sendo determinada pela planta, equipamentos e recursos humanos; 
- Instalações: está relacionada às decisões sobre localização geográfica, tipo de processo produtivo, volume, e ciclo de vida;

- Equipamentos e processos tecnológicos: envolve desde equipamentos utilizados até processos de produção (por projeto, job shop, por lote, linha de montagem);

- Integração vertical e relação com os fornecedores: está relacionada à decisão entre produzir e comprar;

- Recursos humanos: atua sobre políticas existentes, para que mantenham os funcionários motivados, trabalhando em equipe e buscando atingir metas;

- Qualidade: o gerenciamento desta categoria deve especificar como as responsabilidades serão alocadas, que ferramentas de decisão e medição serão utilizadas e quais sistemas de treinamento serão instituídos;

- Escopo e novos produtos: envolve o gerenciamento e a introdução de novos produtos e de operações a partir da amplitude do mix de produtos e processos utilizados;

- Sistemas gerenciais: relaciona-se ao suporte às decisões tomadas e a sua implementação. Requer planejamento, sistemas de controle, políticas operacionais e linhas de autoridade e responsabilidade;

- Relação interfuncional: envolve sistemas gerenciais e mecanismos que possibilitam a interação com as diversas áreas funcionais.

Um dos pontos importantes para a efetivação da estratégia empresarial é a coerência interna e externa da tomada de decisão. A primeira ocorre de duas maneiras: entre as categorias de decisão da produção entre si e entre elas e os critérios competitivos da produção escolhidos. Já a coerência externa ocorre entre os critérios competitivos e a estratégia competitiva da unidade de negócios (WHEELWRIGHT apud BARROS NETO, FENSTERSEIFER e FORMOSO, 2003).

\section{Mapeamento do Fluxo de Valor}

Segundo Rother e Shook (2003), o caminho da produção enxuta é mais árduo do que devia ser, pois os conceitos e técnicas enxutas têm sido utilizados isoladamente. Para mudar essa situação estudando o Sistema Toyota de Produção perceberam o método de mapeamento usado na Toyota para retratar o estado atual e ideal no processo de desenvolvimento de planos de implementação dos sistemas enxutos. Notando que o mesmo tinha um potencial muito além do uso tradicional, formalizaram a ferramenta e construíram um método de treinamento conhecido como Mapeamento do Fluxo de Valor - MFV ou Value Stream Mapping - VSM.

O VSM é uma ferramenta qualitativa capaz de olhar para os processos que agregam valor horizontalmente, enfatizando as atividades, ações e conexões no sentido de criar valor e fazê-lo fluir desde os fornecedores até os clientes finais. Possibilita a identificação de gargalos produtivos, mas 
principalmente uma maneira de pensar sobre o que poderia ser melhorado, no sentido de reduzir os desperdícios inerentes à produção. Segundo Favoni et al. (2013), é usada para descrever em detalhes como a produção opera - Mapa do estado atual - e como deveria operar para criar um fluxo de valor otimizado - Mapa do estado futuro e traduz a filosofia enxuta através dos fluxos de materiais e informações das empresas, proporcionando a visualização da produção e possibilitando identificar os possíveis desperdícios no processo.

O mapa representa visualmente o fluxo de valor de uma empresa, com informações sobre a demanda do cliente, passando por todas as operações de uma determinada família de produto, inclusive com o número de pessoas envolvidas e a forma como os dados fluem na empresa, desenhando o mapa do estado atual. As propostas de melhorias, por exemplo, na produção, no controle do estoque e do produto final, constituem o mapa do estado futuro (ROTHER e SHOOK, 2003).

Visualmente no VSM devem ser representados dados de demanda, fluxo de informações dos clientes, planejamento e controle da produção, informação para os fornecedores, os fornecedores, caixas de processos (tempo de ciclo, setup, mão-de-obra, turnos, etc.), inventários (quantidade e localização), valor agregado, lead time e desperdícios. Rother e Shook (2003) apontam como características essenciais do VSM:

- Ajuda a visualizar mais do que simplesmente os processos individuais, por exemplo, montagem, solda, etc. - você pode enxergar o fluxo todo;

- Ajuda a identificar mais do que os desperdícios. Mapear ajuda a identificar as fontes de desperdícios no fluxo de valor;

- Fornece uma linguagem comum para tratar os processos de manufatura;

- Torna as decisões sobre os fluxos visíveis, de modo que você pode discuti-las. De outro modo, muitos detalhes e decisões no chão de fábrica só acontecem por omissão;

- Junta conceitos e técnicas enxutas, que o ajuda a evitar a implementação de algumas técnicas isoladamente;

- Forma a base de um plano de implementação. Ao desenhar como o fluxo total, de porta a porta, deveria operar - uma parte que falta em muitos esforços enxutos - os mapas do fluxo de valor tornam-se referência para a implementação enxuta. Imagine tentar construir uma casa sem uma planta;

- Mostra a relação entre o fluxo de informação e o fluxo de material. Nenhuma outra ferramenta faz isso; 
- É muito mais útil que ferramentas quantitativas e diagramas de layout que produzem um conjunto de passos que não agregam valor, lead time, distância percorrida, a quantidade de estoque, e assim por diante.

Resumindo, o VSM é mais abrangente que uma técnica comum de mapeamento de processos, com procedimentos definidos e simbologia própria, e por isso representa uma metodologia de referência para a implantação da produção enxuta. Ele caracteriza-se também por ser um método visual de fácil compreensão, que permite enxergar os desperdícios de estoque, de superprodução e de processo, entre outros benefícios, já que permite identificar no detalhe cada processo do fluxo, determinando o lead time por meio de estoques de matéria prima, em processo e produto acabado.

\section{Metodologia}

A pesquisa é um procedimento racional e sistemático que tem como objetivo proporcionar respostas aos problemas que são propostos (GIL, 2002). A pesquisa desenvolve-se ao longo de um processo que envolve inúmeras fases, desde a adequada formalização do problema até a satisfatória apresentação dos resultados. Dessa forma, este estudo está dividido em partes distintas: apresentação da nova estratégia de negócio da unidade de manufatura; levantamento da situação atual da unidade de manufatura, que está passando por uma alteração de sua configuração para atender as necessidades organizacionais da Empresa Alfa; identificação dos gaps que devem ser tratados para implementar a estratégia futura, através do uso do VSM e da abordagem da produção enxuta; e apresentação de propostas de melhoria na manufatura, que possam de fato contribuir no aumento da competitividade da organização, através da apresentação mapa do estado futuro.

Considerando os métodos de pesquisa existentes, quantitativo e qualitativo, e os objetivos da pesquisa definidos anteriormente, este estudo pode ser definido como uma pesquisa do tipo qualitativa, pois visa verificar como ocorrem as práticas dentro de uma organização, indicando qualidades do objeto. Ao mesmo tempo, este estudo caracteriza-se como uma pesquisa aplicada descritiva, pois objetiva gerar conhecimentos para aplicação prática, dirigidos à solução de problemas específicos, envolvendo interesses locais, através de levantamento e descrição de características já conhecidas dos componentes do fenômeno, utilizando levantamentos de dados e observações sistemáticas (ROESCH, 2005).

A metodologia é uma explicação minuciosa, rigorosa e exata das ações desenvolvidas durante a realização de um trabalho de pesquisa. Toda metodologia deve descrever os passos que serão dados para atingir os objetivos propostos (GIL, 2002). Nesse caso é utilizado o método de estudo de caso, já que identifica-se a coleta de dados baseada em fontes de evidências vindas da análise de documentos da empresa, da observação participante, e de entrevistas (YIN, 2005). O 
estudo de caso não é uma técnica específica; na verdade é um meio de organizar dados sociais preservando o caráter unitário do objeto estudado.

$\mathrm{O}$ estudo restringe-se ao âmbito de atuação da Empresa Alfa, especialmente à unidade de manufatura e por isso a construção da hipótese refere-se à possibilidade de melhorar a forma de atuação dessa unidade, realizando um estudo formal da nova estratégia de negócios e do fluxo de valor atual, envolvendo todos os níveis da organização - da alta direção aos funcionários da base.

As técnicas de pesquisa foram: análise de documentos, dados oriundos do monitoramento dos processos gerados via ERP - Enterprise Resource Planning, entrevistas com colaboradores dos processos estudados e das equipes de Engenharia de Processo e Qualidade, além da própria direção da empresa e levantamento de informações dos processos in loco na elaboração do mapa do estado atual e futuro utilizando a ferramenta do VSM. Os resultados obtidos possibilitaram a análise do objeto foco do estudo, sendo que para tanto foram realizadas pesquisas em livros e artigos buscando fundamentação teórica relacionada com o tema proposto para formar uma base de conhecimento.

Quanto às etapas seguidas no desenvolvimento da pesquisa, o trabalho iniciou através da realização de levantamento de dados e entrevistas com os envolvidos, durante 60 dias, com o objetivo de entender a estratégia futura da unidade de manufatura e como a estratégia de operações vai refletir essa mudança. Paralelamente, elaborou-se o mapa do estado atual da manufatura, utilizando o VSM, para entender o fluxo de valor. A partir do VSM foram feitas análises e identificados os gaps do processo, permitindo sugerir o mapa do estado futuro desejado e um detalhamento das propostas de ajuste do fluxo de valor, como resultado do estudo.

A importância deste estudo está na aplicação do VSM, como ferramenta para identificar os gaps existentes entre o estado atual e o futuro desejado, auxiliando assim no processo de ajuste estratégico, pois a manufatura precisa encontrar uma forma eficiente de se adaptar a nova proposta da organização.

\section{Resultados}

\subsection{Trajetória e definição da nova estratégia de negócios}

A Empresa Alfa, que está instalada no Vale dos Sinos, um dos polos industriais de calçados e acessórios do Brasil, durante sua trajetória a empresa passou por duas fases distintas, que de modo simplificado resumem-se em:

- Fase 01, período de 2005 a 2008, onde a empresa contava apenas com a planta fabril e trabalhava sob pedido - Make to Order - MTO, para atender as demandas dos clientes da região grandes fabricantes de calçados; e 
- Fase 02, período de 2008 até o momento, onde a empresa passou a contar, além da fábrica, com uma distribuidora. Com essa alteração, ela passou a apresentar como proposta de valor a oferta de produtos diferenciados - definindo tendência de moda e estilo, lançando novas coleções a cada semestre - tendo todos os materiais a pronta entrega e com a possibilidade de vender qualquer volume, de centímetros a milhares de metros. Com o objetivo de ter maior cobertura de mercado e ir além do Vale dos Sinos, abriu três showrooms - nos polos calçadistas de Jaú/MG, Birigui/SP e São João Batista/SC, ampliou seu grupo de representantes e criou um setor de televenda passando a atender praticamente todas as regiões do país. Para atender essa nova proposta a empresa passou a trabalhar com grandes fornecedores de laminado sintético de poliuretano da China e, por consequência disso, a unidade de manufatura passou a ter como grande objetivo suprir o estoque da distribuidora. Com isso, passou a servir de "bengala" ao novo modelo, passando a trabalhar baseada no conceito Make to Stock - MTS. Casos especiais, considerando o cliente e tipo de produto, continuaram a ser atendidos sob encomenda - mas seus volumes passaram a ser muito reduzidos.

Hoje a empresa é reconhecida como lançadora de moda e de produtos diferenciados. Todo trabalho é feito com muito apelo em tendência de moda: o desenvolvimento é suportado por um trabalho interno em laboratórios de desenvolvimento e investimento em recursos necessários para possibilitar a produção dos produtos que se decidir lançar, e por isso pode-se afirmar que ela trabalha com foco em diferenciação. Custo não está no centro das discussões, inclusive a empresa é conhecida por ter preços mais altos que a concorrência. Isso caracteriza a estratégia de negócio da empresa como um todo já que ambas as unidades, nesse modelo, dão suporte a ela.

Esse modelo, que trouxe muito resultado no passado, hoje apenas permite que a empresa se mantenha no mercado, pois o crescimento está estagnado. Em vista dessa situação, no primeiro trimestre de 2013 iniciou-se na um trabalho de cunho estratégico para tornar a empresa competitiva e voltar a crescer, cuja ação determinante é passar a trabalhar com duas unidades de negócio distintas, cada uma com uma estratégia de negócio própria dando suporte a estratégia competitiva da empresa que se manterá a mesma. Assim, a empresa Alfa passará a contar com uma grande distribuidora, que terá como fornecedores indústrias chinesas de produto acabado e uma planta de manufatura que apenas trabalhará sob encomenda - deixando de ser focada no conceito MTS para voltar ao modelo MTO. Essa grande alteração, caracteriza o início de uma terceira fase na trajetória da organização.

Quadro 1 - Estratégias de Operações da Unidade de Manufatura: Critérios Competitivos

\begin{tabular}{|c|c|c|}
\hline CRITÉRIOS COMPETITIVOS & ESTRATÉGIA ATUAL & ESTRATÉGIA FUTURA \\
\hline CUSTO & Qualificador & Qualificador \\
\hline QUALIDADE & Qualificador & Ganhador de pedido \\
\hline
\end{tabular}




\begin{tabular}{|c|c|c|}
\hline FLEXIBILIDADE & Ganhador de pedido & Ganhador de pedido \\
\hline ENTREGA & Qualificador & Ganhador de pedido \\
\hline INOVAÇÃO & Ganhador de pedido & Qualificador \\
\hline
\end{tabular}

Fonte: Autoria própria (2014)

Nesta pesquisa, o estudo realizado está focado na planta de manufatura, que é a unidade onde haverá mais impactos decorrentes da decisão tomada, pois na Distribuidora o modelo vigente praticamente não muda. Já na unidade Manufatura a mudança é bem mais drástica, pois o novo objetivo é muito diferente do que estava definido até então - o modelo MTS deve deixar de existir para dar lugar ao MTO, onde, pelo fato da fábrica passar a atender sob encomenda, produtos diferenciados para uma indústria que busca estoque zero, com prazos de entrega reduzidos e com qualidade superior, todas as diretrizes e metas operacionais deverão ser revistas. Com isso, essa unidade também deixa de focar no mercado como um todo para focar no atendimento a clientes. Vale destacar que, ela conta com um suporte interno muito forte para a execução da mudança proposta pela direção: existem investimentos em fabricação e condições de infraestrutura, há engajamento das equipes, e a área de desenvolvimento de produto é o grande ponto forte da unidade, que será explorado.

Dessa forma, a partir do entendimento da mudança esperada pela organização, foi possível caracterizar objetivamente a estratégia de operações atual e a estratégia de operações futura da unidade de manufatura, que dará suporte a nova estratégia de negócio proposta. As estratégias estão detalhadas nos Quadros 1 e 2.

Vale destacar que a estratégica genérica por trás de ambas não se alterou e se mantém com foco em diferenciação pura, a principal mudança se dá na definição dos critérios competitivos onde o critério de inovação passa a ser qualificador e os critérios de entrega e qualidade passam a ser ganhadores de pedido, junto com o critério de flexibilidade.

Em função dessa alteração nos critérios competitivos, há necessidade de adequar a forma de atuação frente às categorias de decisão, sendo que é possível afirmar que a empresa não necessita alterar o como atende as decisões de capacidade e sistemas gerencias. No entanto, as demais categorias necessitam de um replanejamento, que resumidamente engloba decisões a respeito da necessidade de diminuir o lead time de entrega, criação de um fluxo contínuo, melhorar velocidade de resposta e ciclo logístico, incluindo desenvolvimento de fornecedores, assistência técnica, aproximação do cliente e desenvolvimento da área de recursos humanos.

Quadro 2 - Estratégias de Operações da Unidade de Manufatura: Categorias de Decisão

\section{CATEGORIAS DE DECISÃO}

\section{ORIENTAÇÃO ATUAL X FUTURA}




\begin{tabular}{|c|c|}
\hline $\begin{array}{c}\text { CATEGORIAS DE } \\
\text { DECISÃO }\end{array}$ & ORIENTAÇÃO ATUAL X FUTURA \\
\hline CAPACIDADE & $\begin{array}{l}\text { Utilizar ao máximo a capacidade instalada - que atualmente é de } 7.000 \mathrm{~m} \text { material/dia, } \\
\text { para atender as demandas. O que muda apenas é o objetivo, que antes era para reposição } \\
\text { de estoque da distribuidora e passará a ser para produzir contra pedido, com a maior } \\
\text { velocidade possível. Esta já é uma sistemática utilizada pelos concorrentes que produzem } \\
\text { produtos exclusivos. Não há necessidade de adequações para atender a nova estratégia. }\end{array}$ \\
\hline INSTALAÇÕES & $\begin{array}{l}\text { Quanto à localização, a unidade já está próxima ao maior mercado consumidor dos seus } \\
\text { produtos. Para a estratégia anterior trabalhava com empresas de logística, para tender os } \\
\text { mercados mais distantes. No caso da nova estratégia, o foco será atender apenas os Polos } \\
\text { Calçadistas do Vale dos Sinos/RS e de São João Batista/SC, que estão mais perto, pois } \\
\text { assim será possível também se aproximar das áreas de desenvolvimento de produto dos } \\
\text { clientes, para alavancar o grande objetivo do novo posicionamento: produção de produtos } \\
\text { sob encomenda. Quanto ao fluxo de produção, hoje é descontínuo em função do tipo de } \\
\text { equipamento existente e da lógica MTS. Com a alteração, não será posível alterar as } \\
\text { instalações, mas trabalhos buscando o fluxo contínuo podem ser implementados, inclusive } \\
\text { para reduzir o lead time. Hoje na lógica MTS se admite } 14 \text { dias para a entrega e na lógica } \\
\text { MTO será necessário reduzir para níveis de } 7 \text { dias. }\end{array}$ \\
\hline $\begin{array}{l}\text { EQUIPAMENTOS E } \\
\text { PROCESSOS } \\
\text { TECNOCLÓGICOS }\end{array}$ & $\begin{array}{l}\text { Dispõem de equipamentos necessários às características dos produtos, mantendo máquinas } \\
\text { menores que podem ser usadas para diversas aplicações. A empresa possui know how no } \\
\text { ramo de atuação e ótima estrutura tecnológica. Para atender a estratégia anterior, em } \\
\text { função dos desenvolvimentos das coleções serem semestrais, era possível antecipar a } \\
\text { definição de ferramentais e processos. Para a estratégia futura será necessário realizar um } \\
\text { trabalho forte junto a fornecedores de ferramentas, encurtar tempos de desenvolvimento de } \\
\text { produto e dispor de opções tecnológicas principalmente quanto a estampas. }\end{array}$ \\
\hline $\begin{array}{l}\text { INTEGRAÇÃO } \\
\text { VERTICAS E } \\
\text { RELAÇÃO COM } \\
\text { FORNECEDORES }\end{array}$ & $\begin{array}{l}\text { Boa relação com fornecedores, mas que atualmente tem o poder de barganha. Consegue-se } \\
\text { ter excelência no atendimento das necessidades de compra, mas o maior dificultador é o } \\
\text { fato de serem chineses e por isso, hoje para suprir qualquer problema de embarque ou } \\
\text { trasitime, trabalha-se com grandes estoques de segurança. Para melhorar resultados e } \\
\text { garantir a adequação das matérias-primas às necessidades dos clientes na nova estratégia, } \\
\text { preciso desenvolver fornecedores mais próximos e avaliar o ciclo logístico e os modais } \\
\text { utilizados nas entregas. }\end{array}$ \\
\hline $\begin{array}{l}\text { RECURSOS } \\
\text { HUMANOS }\end{array}$ & $\begin{array}{l}\text { A estratégia se desdobra apenas até o nível operacional, mas as políticas e práticas de } \\
\text { recursos humanos, incluindo administração, seleção e treinamento, são muito engessadas e } \\
\text { conservadoras. Faltam políticas claras de desenvolvimento, definições de cargos e salários } \\
\text { e estrutura de autoridade e responsabilidades. Além disso, a comunicação interna } \\
\text { deficiente. Essa área necessita de atenção especial e o desenvolvimento de um trabalho de } \\
\text { mudança independente da estratégia. Mas claro que no modelo novo, as capacidade da } \\
\text { equipe estarão sendo requeridas de forma mais contundente. }\end{array}$ \\
\hline QUALIDADE & $\begin{array}{l}\text { Possui certificação ISO } 9001 \text {, tendo sistemáticas definidas de controle de processo e } \\
\text { monitoramento de desempenho, assim como de melhoria. Falta de uma estrutura de } \\
\text { assistência técnica, mais presente junto aos clientes. Hoje há excesso de burocracia, o que } \\
\text { trava o processo. No modelo atual essa questão é administrada de forma tranquila, mas } \\
\text { para atender a nova estratégia é preciso simplificar as sistemáticas e metodologias } \\
\text { utilizadas, além de remodelar a área de assistência técnica. }\end{array}$ \\
\hline $\begin{array}{l}\text { ESCOPO E NOVOS } \\
\text { PRODUTOS }\end{array}$ & $\begin{array}{l}\text { Empresa trabalha com produtos diferenciados e é formador de tendência, oferecendo } \\
\text { produtos de qualidade superior. Por isso é uma marca forte no mercado do calçado. A área } \\
\text { de pesquisa e desenvolvimento é muito desenvolvida, baseada em muita pesquisa de } \\
\text { moda. O desenvolvimento em si, na estratégia atual, consegue atender as necessidades da } \\
\text { distribuidora, com muita inovação e criatividade, permitindo o lançamento de coleções } \\
\text { inteiras. Para a nova estratégia, a principal mudança se dá no fato da pesquisa passar a } \\
\text { estar mais ligada às áreas de desenvolvimento dos clientes, tendo como base apenas os } \\
\text { estudos realizados internamente. }\end{array}$ \\
\hline $\begin{array}{c}\text { SISTEMAS } \\
\text { GERENCIAIS }\end{array}$ & $\begin{array}{l}\text { Gestão compartilhada, com uso do BSC - Balanced Scored Card para monitorar o } \\
\text { desempenho e o sistema de premiação é com base no atendimento das metas estabelecidas. } \\
\text { A unidade de negócio trabalha com base em orçamento empresarial e utiliza como } \\
\text { principal ferramenta de apoio o sistema informatizado da empresa (ERP - Enterprise } \\
\text { Resource Planning), com informações integradas. Para ambas as estratégias a forma de } \\
\text { atender a essa categoria está adequada, sendo necessário apenas revisar metas e objetivos. }\end{array}$ \\
\hline
\end{tabular}




\begin{tabular}{|c|l|}
\hline $\begin{array}{c}\text { CATEGORIAS DE } \\
\text { DECISÃO }\end{array}$ & \multicolumn{1}{c|}{ ORIENTAÇÃO ATUAL X FUTURA } \\
\hline $\begin{array}{c}\text { RELAÇÃO } \\
\text { INTERFUNCIONAL }\end{array}$ & $\begin{array}{l}\text { Há uma boa estrutura organizacional e sistemas de controle que possibilitam a integração } \\
\text { das áreas, o que atende de modo satisfatório a estratégia atual, no entanto para a } \\
\text { velocidade e assertividade necessárias à nova estratégia um trabalho de readequação dessa } \\
\text { integração é fundamental para tornar o processo mais coeso. }\end{array}$ \\
\hline
\end{tabular}

Fonte: Autoria própria (2014)

Além das questões apresentadas, destaca-se que hoje, $80 \%$ da capacidade da fábrica está destinada à produzir produtos que suprem o estoque da distribuidora. Assim, para atender a nova estratégia deve-se trabalhar a força de vendas dessa unidade, prospectar clientes e reorganizar o trabalho para que os $80 \%$ sejam substituídos por novos projetos de produtos sob encomenda, cuja produção será realizada apenas a partir de pedidos firmes, que imediatamente após concluídos, deverão ser faturados e enviados aos clientes.

Esse trabalho na frente comercial e de desenvolvimento de produto está sendo conduzido pelo diretor da unidade de manufatura, mas há uma projeção que a inversão completa da situação ocorra num prazo de até 24 meses. Enquanto isso é necessário preparar a fábrica para dar respostas diferentes das atuais, pois a ótica da produção Make to Stock - MTS para a produção Make to Order - MTO muda bastante, principalmente no que diz respeito ao relacionamento com o cliente, como pode ser verificado nas Figuras 2 e 3, que demonstram o modelo atual e o modelo futuro.

Figura 2 - Modelo atual

\begin{tabular}{|c|c|c}
$\begin{array}{c}\text { PERIODO DE DESENVOLVIMENTO } \\
\text { DE PRODUTO }\end{array}$ & $\begin{array}{c}\text { ESTOQUE DE } \\
\text { PRODUTO } \\
\text { ACABADO }\end{array}$ & VENDA PARA OS CLIENTES \\
\hline 6 MESES & PRONTA ENTREGA \\
COLEÇÃO E CADA COLEÇÃO É DE 6 MESES.
\end{tabular}

Fonte: Autoria própria (2014)

No modelo atual, o relacionamento com o cliente, inicia após o lançamento da coleção, com a oferta dos produtos a pronta entrega. Nesse cenário todo o trabalho de desenvolvimento de produto, com base em pesquisas de moda e tendências, definição dos artigos, testes de produção e produção já propriamente dita está concluído, havendo apenas necessidade de ir repondo o estoque.

No modelo futuro, o cenário muda ao passo que o relacionamento com o cliente, inicia ainda antes de qualquer outra atividade, já que é a partir de suas demandas específicas que ocorre o start do processo de desenvolvimento de produto, definição das características técnicas e visuais, aprovação do produto, realização dos testes de produção - pilotagem e aprovação do primeiro lote para entrega. Somente com essas etapas concluídas ocorre uma relação de compra e venda que está condicionada ao atendimento das necessidades do cliente. 


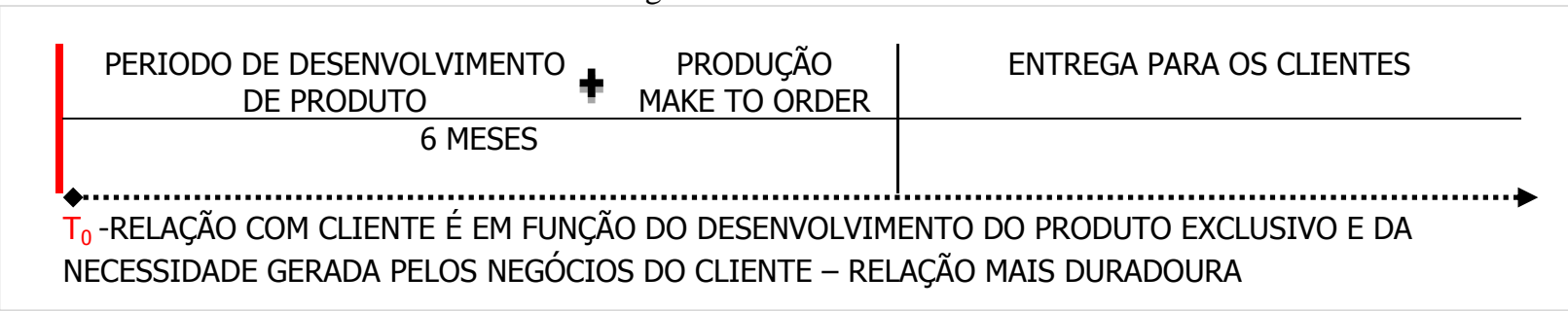

Fonte: Autoria própria (2014)

\subsection{Elaboração do mapa do estado atual}

Para entender de forma clara a situação atual, optou-se por aplicar o VSM na família de produto mais representativa, oriunda processo de manufatura, com objetivo de desenhar o mapa do estado atual, para partir dele definir as ações prioritárias para adequação à estratégia planejada.

Para a elaboração do VSM realizou-se um levantamento dos produtos vendidos sob encomenda no primeiro semestre de 2014 - período de $1^{\circ}$ de janeiro de 2014 a 30 de junho de 2014. A partir desses dados, foi definida em que família de produtos focalizar o estudo, pois conforme Rother e Shook (2003), os consumidores da empresa, preocupam-se com produtos específicos, não com todos os produtos. Para aplicação do VSM entende-se família como um grupo de produtos que passam por etapas semelhantes de processamento e utilizam equipamentos comuns nos seus processos. Como o mix de produtos da empresa Alfa é complicado, para definir a família, foi elaborada uma matriz com as etapas do processo de produção/equipamentos em um eixo e os produtos em outro eixo, conforme modelo da Figura 4.

Figura 4 -Matriz para escolha da família de produtos

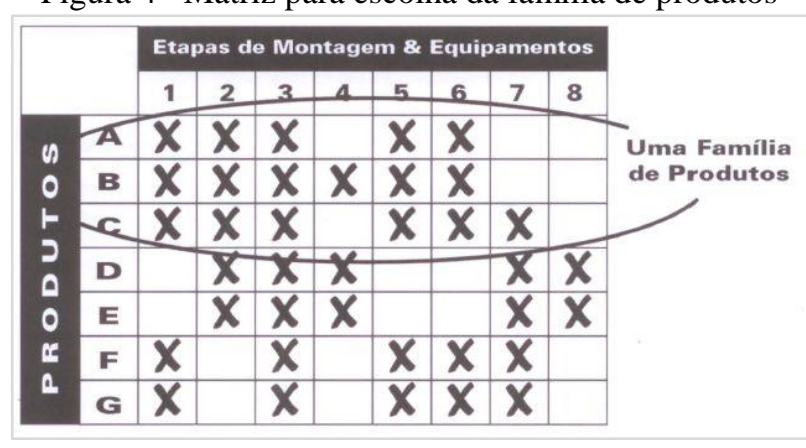

Fonte: Rother e Shook (2003)

A tabela desenvolvida no estudo, a partir do faturamento do primeiro semestre como já foi dito, contempla um total de 568 produtos, por isso, para ilustrar, segue na Tabela 1 apenas um recorte de 12 itens que compõem a mesma.

A partir da análise da matriz, identificou-se que 436 produtos passam pelo processo Espalmar: 2 cabeças, representando $77 \%$ do total, 293 produtos passam pelo processo Lacar (novo) e representam $52 \%$ do total, todos os produtos passam pela revisão e os demais processos fazem parte de menos de $20 \%$ do total de itens. 
Assim, fazendo uma seleção dos produtos que passam pelos três processos mais significativos: espalmar: 2 cabeças, lacar (novo) e revisão, chegamos a 244 itens que representam $43 \%$ do total de itens, definindo a família de produtos selecionada. Vale registrar que pela ótica do faturamento, a família escolhida gerou $\mathrm{R} \$$ 3.626.986,10 de recebíveis, frente aos $\mathrm{R} \$ 7.569 .279,95$ do faturamento total do semestre, representando $48 \%$ do total, confirmando que de fato é o fluxo de valor mais representativo na ótica dos clientes. Após escolhida a família de produtos, foi elaborado o mapa do estado atual, conforme apresentado na Figura 5.

Tabela 1 - Matriz de escolha da família a ser estudada

\begin{tabular}{|c|c|c|c|c|c|c|c|c|c|c|c|c|c|}
\hline \multirow[b]{2}{*}{ Е్ల } & \multirow[b]{2}{*}{ 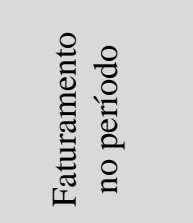 } & \multicolumn{12}{|c|}{ Processos / equipamentos } \\
\hline & & 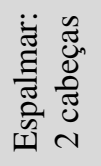 & 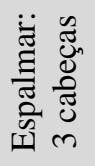 & 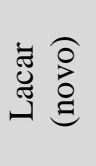 & 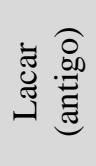 & 芯 & 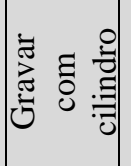 & 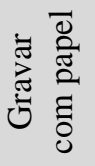 & 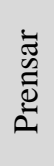 & : & $\frac{\stackrel{\Xi}{\Xi}}{\bar{\Xi}}$ & 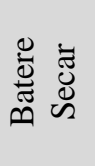 & 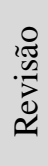 \\
\hline $\mathrm{AB}$ & $\mathrm{R} \$ 8.459,25$ & & $\mathrm{X}$ & $\mathrm{X}$ & $\mathrm{X}$ & & $\mathrm{X}$ & & & $\mathrm{X}$ & & $\mathrm{X}$ & $\mathrm{X}$ \\
\hline PK & $\mathrm{R} \$ 8.382,79$ & $\mathrm{X}$ & & $\mathrm{X}$ & & & & & & & & & $\mathrm{X}$ \\
\hline $\mathrm{BG}$ & $\mathrm{R} \$ 8.154,70$ & $\mathrm{X}$ & & & & & & & & & & & $\mathrm{X}$ \\
\hline JN & $\mathrm{R} \$ 7.768,80$ & $\mathrm{X}$ & & $\mathrm{X}$ & & & $\mathrm{X}$ & & & & & & $\mathrm{X}$ \\
\hline $\mathrm{AC}$ & $\mathrm{R} \$ 7.746,73$ & $\mathrm{X}$ & & $\mathrm{X}$ & & & & & & & & & $\mathrm{X}$ \\
\hline $\mathrm{AD}$ & $\mathrm{R} \$ 7.745,90$ & & $\mathrm{X}$ & & & & & & & & & & $\mathrm{X}$ \\
\hline $\mathrm{AF}$ & $\mathrm{R} \$ 7.616,70$ & $\mathrm{X}$ & & & & & & & & & & & $\mathrm{X}$ \\
\hline $\mathrm{RD}$ & $\mathrm{R} \$ 7.578,34$ & & $\mathrm{X}$ & & & & & & & & & & $\mathrm{X}$ \\
\hline SE & $\mathrm{R} \$ 7.470,01$ & $\mathrm{X}$ & & $\mathrm{X}$ & & & & & & & & & $\mathrm{X}$ \\
\hline FG & $\mathrm{R} \$ 7.453,92$ & & $\mathrm{X}$ & & & & & & & & & & $\mathrm{X}$ \\
\hline SW & $\mathrm{R} \$ 7.402,77$ & & $\mathrm{X}$ & $\mathrm{X}$ & & & $\mathrm{X}$ & & & & & & $\mathrm{X}$ \\
\hline GE & $\mathrm{R} \$ 7.288,50$ & & & $\mathrm{X}$ & $X$ & $X$ & $\mathrm{X}$ & & & & & & $\mathrm{X}$ \\
\hline
\end{tabular}

Fonte: Autoria própria (2014)

\subsection{Identificação dos gaps do processo para atender a nova estratégia de negócio}

A partir da análise do mapa do estado atual, o que mais chama a atenção é que, do lead time total, correspondente a 874,5 h (99,4 dias), apenas 0,48 min (0,008 h) são dispendidas em tempo de processamento em si, ou seja, tempo dos elementos de trabalho que efetivamente transformam o produto de uma maneira que o cliente está disposto a pagar. Com esses dados pode-se afirmar que o percentual de atividade no processo que agregam valor é de $0,001 \%$.

Dessa forma a necessidade de redução do lead time do fluxo porta a porta e o aumento do percentual de atividades que agregam valor no processo são os dois maiores gaps do processo. Complementarmente é preciso ainda destacar os seguintes aspectos:

- O estoque da matéria-prima base é muito grande e é o fator que gera o maior desperdício no fluxo;

- Existem muitos pontos de estoque intermediário e os mesmos não são proporcionais às demandas dos processos subsequentes; 
- Todo sistema de produção é empurrado e não puxado, ou seja, os processos produzem material independente das necessidades reais dos processos seguintes. Assim pode-se afirmar que não há nenhuma "puxada" à qual o fluxo de valor possa responder;

- Os setups são elevados, variando de 12 a 23 minutos cada;

- Cada processo opera como uma "ilha isolada" não conectada a qualquer cliente seguinte, pois cada um possui sua própria programação;

- A programação do faturamento e embarque dos produtos, definido pela área comercial, possui programação própria, estando desconectada do PCP, e por consequência do processo. 
Figura 05 - Mapa do Estado Atual da Unidade de Manufatura da Empresa Alfa

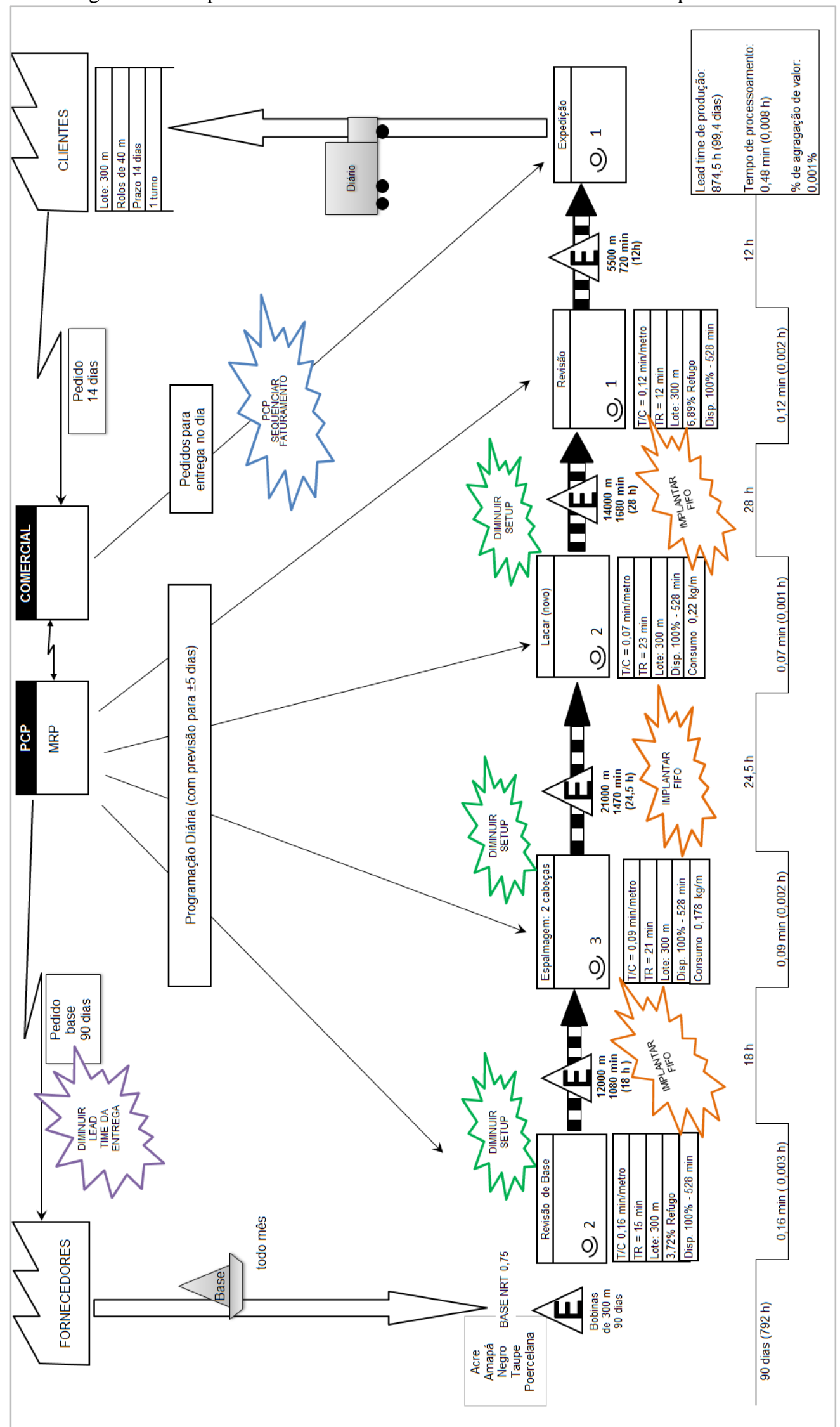

Fonte: Autoria própria (2014)

\subsection{Melhorias propostas a partir dos gaps identificados}


Após a elaboração do VSM, os pontos a serem trabalhados já são evidentes sob a ótica da produção enxuta, pois é fácil identificar as fontes de desperdícios. As principais questões a serem trabalhadas foram sinalizadas no próprio mapa do estado atual, conforme apresentado também na Figura 5.

Dessa forma, entendendo o fluxo da informação e dos materiais no mapa, juntamente com as definições de valor sob a ótica do cliente, pode-se definir como ações de melhoria a serem executadas:

- Reduzir estoque da matéria-prima base - como resultado a ser buscado, sugere-se ter como meta trabalhar com máximo de 7 dias, programando entregas semanais. Apenas com a implementação desta ação ocorre uma redução de $91,7 \%$ no lead time total;

- Reduzir os estoques intermediários através da implantação de sistema FIFO, onde o primeiro a entrar é o primeiro a sair entre os dois processos e manter um fluxo entre eles. Se o FIFO encher o processo fornecedor para de produzir até o cliente ter esgotado parte de seu estoque;

- Reorganizar priorização da produção, readequando as atividades do PCP, definindo um processo puxador, que é o processo controlado pelos pedidos dos clientes. Nesse caso o processo puxador seria a revisão de base;

- Organizar o faturamento e expedição dos pedidos a partir do PCP, para com isso atender as demandas dos clientes de forma mais adequada;

- Reavaliar as sistemáticas de TRF - troca rápida de ferramentas - implantada para reduzir os tempos de setups. Essa ação auxiliar a tornar os processos capazes de responder às mudanças mais rapidamente, além de permitir mais uma redução nos estoques intermediários do FIFO.

Com base nas ações de melhoria sugeridas, realizou-se a elaboração de uma proposta de mapa do estado futuro, para ser possível visualizar de forma mais clara os benefícios que elas podem trazer. Esse mapa é apresentado na Figura 6.

\section{Conclusões}

Neste artigo é realizado um estudo de caso, onde temos a unidade de manufatura da Empresa Alfa como objeto principal. Ela, que vive um momento de adequação da sua estratégia de negócio para atender a mudança de posicionamento da corporação frente ao mercado, precisa tornar-se competitiva e atender as necessidades organizacionais. Frente a esse cenário, o objetivo central deste artigo é apresentar os gaps do processo de manufatura atual para atender a mudança planejada.

Para conseguir chegar ao resultado esperado fez-se uso do VSM, ferramenta que permitiu enxergar os gaps do processo de forma objetiva e após foi utilizada para desenhar o mapa do estado futuro desejado, já que a mesma permite identificar desperdícios e propor soluções de melhoria visando a geração de valor para o cliente. Além disso, através das entrevistas, análises de 
documentos e levantamentos in loco, foi possível detalhar de forma concisa o estado atual e futuro da unidade, podendo concluir que para atender os critérios competitivos definidos como ganhadores de pedidos - flexibilidade, qualidade e entrega, é necessário reduzir o lead time total de atravessamento, diminuir os prazos de entrega e garantir as condições necessárias para a produção de um mix de produtos cada vez maior, com lotes de produção cada vez menores.

O estudo em si, permitiu também contextualizar a trajetória da empresa e a nova estratégia de negócios da unidade de manufatura, a partir da qual identificou as grandes diretrizes para a grande mudança que necessita ser promovida. Ao mesmo tempo, a clareza alcançada no estudo, criou condições para que a apresentação das propostas de melhorias, baseadas no mapa do estado futuro, fossem objetivas e plenamente factíveis, já que o modelo demonstra como realizar a incorporação dos princípios enxutos no contexto do sistema produtivo analisado.

Devido às limitações do método de análise utilizado, percebe-se que o desenvolvimento de produtos necessita devida atenção para tornar-se mais ágil e reduzir o tempo entre seu início e a colocação de pedido firme pelos clientes. Também nesse caso, não foram consideradas as demais famílias de produtos produzidas na unidade, sendo que a sua fabricação concomitante à família estudada torna mais complexo o ambiente analisado.

É importante ressaltar, que as mudanças propostas além de criar a melhor condição para o atendimento aos clientes, também permitem alavancar o resultado econômico-financeiro da unidade de manufatura e por consequência da empresa: quanto menor for o lead time de produção, menor o tempo entre pagar pela matéria-prima e receber pelo produto acabado produzido com esses materiais, pois o lead time menor está relacionado com o número de giros do estoque e com isso, evita-se perdas com estoques, melhorando o fluxo financeiro da organização; e com a redução do prazo para entrega e o aumento da produção de lotes cada vez menores de produtos diferenciados, aumenta a relação de confiança com o cliente, que é critica nesse tipo de negócio, e com isso estima-se o aumento do faturamento, pelo aumento de número de pedidos e margens de contribuição melhores podem estar na pauta das negociações.

Para concluir, é necessário tornar evidente a relevância deste estudo, principalmente pelo fato do mesmo criar condições de desenvolver de forma imediata as primeiras mudanças que levarão a unidade de manufatura obter resultados diferenciados, suprindo os gaps identificados e colocando o cliente no centro de duas atividades. Outra contribuição também se dá pelo fato de trazer a tona o contexto geral da mudança que está ocorrendo na empresa e na unidade de manufatura em si, criando um consenso ao redor do tema, podendo sobre este aspecto, gerar maior comprometimento de todos com o processo de mudança. 
Figura 06 - Mapa do Estado Futuro da Unidade de Manufatura da Empresa Alfa

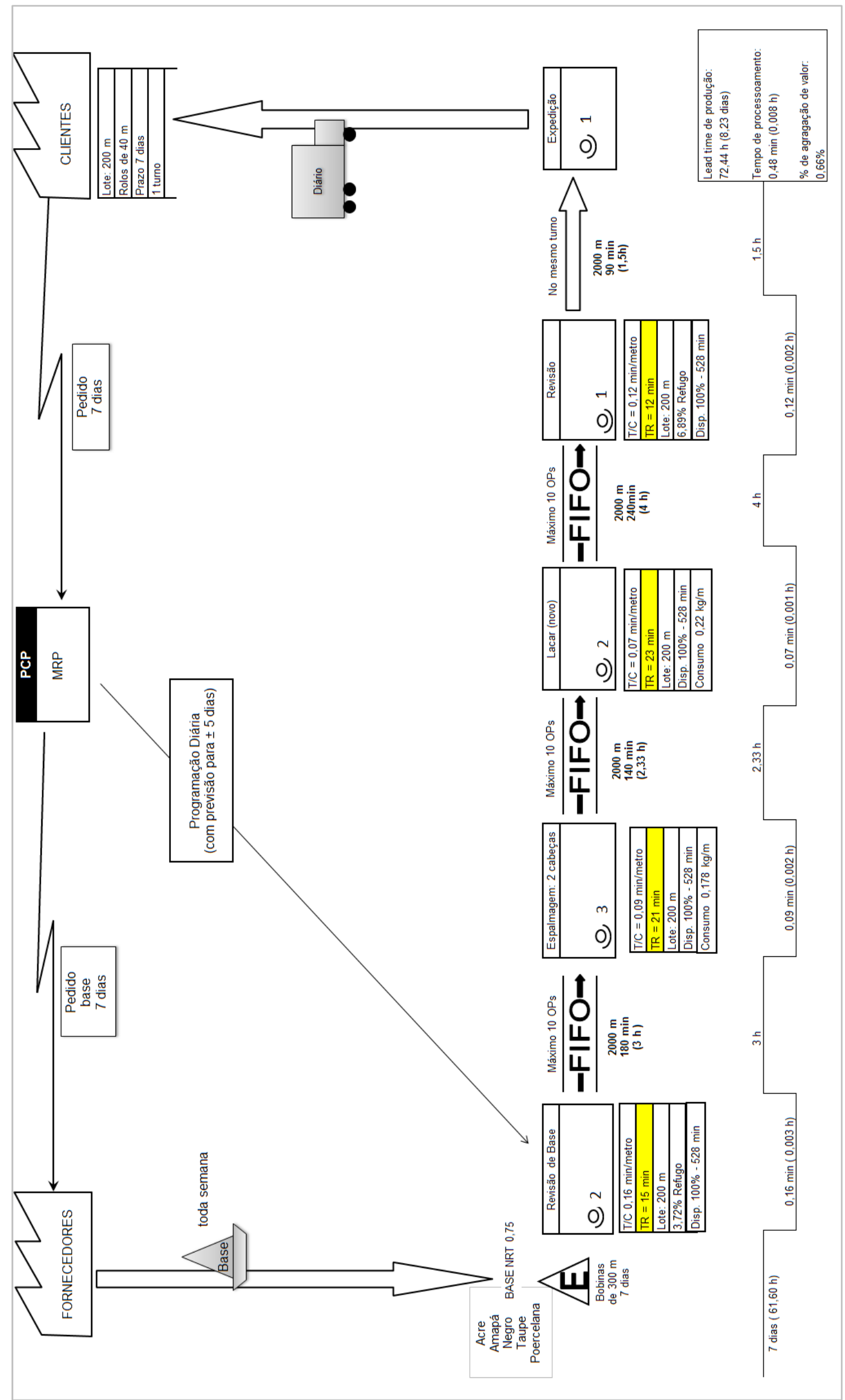

Fonte: Autoria própria (2014) 


\begin{abstract}
The current competitive edge is defined by the decision of what to do better and different from others and this necessarily implies choosing among a set of activities, which have the greatest potential to add value to the company (PAIVA, CARVALHO E FENSTERSEIFER, 2004). Given this context, we have a manufacturing unit of Alpha Company - a company of textile coating, which is changing its business strategy to meet the changing shape of the organization to compete. Facing this this fact, the main objective of this paper is to present the gaps of the current manufacturing process through the use of Value Stream Mapping - VSM to meet the change in its business strategy. Furthermore, the article presents the history of the company and the new strategy of the manufacturing business unit, a map detailing of the flow of the current value and identifying areas of improvement needed for it to be successful. Thus, this study is characterized as an applied descriptive research, where the research method used was the case study with qualitative approach, through the use of information systems in the organization, interviews and information gathering spot. As a result of the search of the desired future state map is presented, detailing a set of actions to suit manufacturing facility, making it competitive to leverage the company's results.
\end{abstract}

Key-words: strategy; business strategy; operations strategy; value stream mapping; VSM.

\title{
Referências
}

DRUCKER, P. F., Fator humano e desempenho: o melhor de Drucker sobre Administração. São Paulo: Pioneira, 1981.

FAVONI, C. et.al. Produção enxuta: aplicação da ferramenta mapa do fluxo de valor (MFV) em uma indústria de calçados femininos. Gestão Industrial. v. 09, n. 02: p. 346-365, 2013.

GIL, A. C. Como elaborar projetos de pesquisa. 4. ed. São Paulo: Atlas, 2002.

MAIA, J. L.; CERRA, A. L.; ALVES FILHO, A. C. Inter-relações entre Estratégia de Operações e Gestão da Cadeia de Suprimentos: Estudos de Caso no Segmento de Motores para Automóveis. Gestão \& Produção, v.12, n.3, p.377-391, 2005.

BARROS NETO, J.P.; FENSTERSEIFER, J. E.; FORMOSO, C. T. Os Critérios Competitivos da Produção: um Estudo Exploratório na Construção de Edificações. RAC, v. 7, n. 1, p. 67-85, 2003.

PAIVA, E. L.; CARVALHO JR., J. M. de; FENSTERSEIFER, J. E. Estratégia de produção e de operações: conceitos, melhores práticas e visão de futuro. Porto Alegre: Bookman, 2004.

PORTER, M. Vantagem Competitiva. Rio de Janeiro: Campus, 1989.

PORTER, M. Estratégia Competitiva: Técnicas para análise de indústrias e concorrência. Rio de Janeiro: Campus, 1991.

ROESCH, S. M. A. Projetos de estágio e de pesquisa em administração: guia para estágios, trabalhos de conclusão, dissertações e estudos de caso. 3. ed. São Paulo: Atlas, 2005.

ROTHER, M.; SHOOK, J. Aprendendo a Enxergar: mapeando o fluxo de valor para agregar valor e eliminar desperdício. Lean Enterprise Institute do Brasil, 2003.

YIN, R. K. Estudo de caso: planejamento e métodos. 3. ed. Porto Alegre: Bookman, 2005.

\section{Dados dos autores:}

\section{Nome completo: Gisleine Schorn}

Filiação institucional: Universidade do Vale do Rio dos Sinos - UNISINOS

Função ou cargo ocupado: Estudante de Pós-Graduação Lato Senso 
Endereço completo para correspondência: Rua São Caetano, 785/302, Centro - São Leopoldo/RS, Brasil, CEP: 93010-090.

Telefone para contato: (51) 9694-1197

E-mail: gisleine.schorn@gmail.com

Nome completo: André Seidel

Filiação institucional: Centro Universitário La Salle - UNILASALLE

Função ou cargo ocupado: coordenador

Endereço completo para correspondência: Av. Victor Barreto, 2288

Telefones para contato: (51) 93715347

E-mail: aseidel@unilasalle.edu.br

Submetido: 2015-01-29

Aceito 2015-05-07 